\title{
Capim-tanzânia submetido a combinações entre intensidade e freqüência de pastejo
}

\author{
Rodrigo Amorim Barbosa ${ }^{(1)}$, Domicio do Nascimento Júnior(2), Valéria Pacheco Batista Euclides ${ }^{(1)}$, \\ Sila Carneiro da Silva ${ }^{(3)}$, Ademir Hugo Zimmer ${ }^{(1)}$ e Roberto Augusto de Almeida Torres Júnior ${ }^{(1)}$
}

\begin{abstract}
(1)Embrapa Gado de Corte, Rodovia BR 262, Km 04, Caixa Postal 154, CEP 79002-970 Campo Grande, MS. E-mail: rodrigo@cnpgc.embrapa.br, val@cnpgc.embrapa.br, zimmer@cnpgc.embrapa.br, rtorres@cnpgc.embrapa.br (2)Universidade Federal de Viçosa, Dep. de Zootecnia, Av. PH Rolfs. s/no, Campus Universitário, CEP 36570-000 Viçosa, MG. E-mail: domicio@ufv.br (3)Escola Superior de Agricultura Luiz de Queiroz, Av. Pádua Dias, no 11, Caixa Postal 9, CEP 13418-900 Piracicaba, SP. E-mail: scdsilva@esalq.usp.br
\end{abstract}

Resumo - O objetivo deste trabalho foi avaliar as características estruturais e a produção de forragem do capimtanzânia (Panicum maximum Jacq. cv. Tanzânia) sob condições de pastejo rotativo, em um Latossolo Vermelho distrófico, num experimento realizado em Campo Grande, MS. Os tratamentos corresponderam a combinações entre três condições de pré e duas condições de pós-pastejo, e foram alocados às unidades experimentais segundo um delineamento de blocos completos casualizados, com três repetições e arranjo fatorial 3x2. As condições de prépastejo de 90, 95 e 100\% de interceptação de luz (IL) foram atingidas consistentemente com alturas de dossel em torno de 60,70 e $85 \mathrm{~cm}$, respectivamente. Pastejos iniciados com $90 \%$ de IL resultaram em maior número de ciclos de pastejo em relação aos iniciados com 95 e 100\% de IL. O acúmulo de forragem foi maior em pastejos realizados com $95 \%$ do que com 90 ou 100\% de IL, mas não houve diferença entre os tratamentos de 90 e $95 \%$ de IL para acúmulo de folhas. O acúmulo de colmos aumentou após os $95 \%$ de IL, indicando a importância da frequiência de pastejo como maneira de controlar a estrutura e a composição do dossel.

Termos para indexação: Panicum maximum, altura do dossel, interceptação de luz, acúmulo de forragem, manejo do pastejo.

\section{Tanzânia grass subjected to combinations of intensity and frequency of grazing}

\begin{abstract}
The objective of this work was to evaluate the structural characteristics and herbage accumulation of Tanzania grass pastures (Panicum maximum cv. Tanzania) under rotationally grazing, in an Oxisol, in experiment carried out at Campo Grande, MS. Treatments corresponded to combinations of three pre and two post-grazing conditions, and were allocated to experimental units according to a complete randomized block design, with three replications and a $3 \times 2$ factorial arrangement. The pre-grazing conditions of 90,95 and $100 \%$ light interception (LI) were achieved consistently with swards heights around 60,70 and $85 \mathrm{~cm}$, respectively. Grazings at $90 \% \mathrm{LI}$ resulted in larger number of grazing cycles than grazings at 95 and 100\% LI. Total herbage accumulation was larger with grazings at 95\% than at 90 and $100 \%$ LI, but there was no difference between the 90 and $95 \%$ LI treatments for leaf accumulation. Accumulation of stem material increased substantially after $95 \% \mathrm{LI}$, indicating the importance of grazing frequency as a means of controlling sward structure and composition.
\end{abstract}

Index terms: Panicum maximum, sward height, light interception, herbage accumulation, grazing management.

\section{Introdução}

A baixa produtividade de áreas de pastagens no Brasil é uma das principais causas da baixa rentabilidade e competitividade dos sistemas de produção animal em relação a outros sistemas agrícolas. Isso se deve, em parte, à falta de conhecimento dos limites de utilização das plantas forrageiras nos mais variados ambientes. No entanto, a preocupação sempre esteve centrada em questões como: estacionalidade de produção e valor nutritivo, razão pela qual tem existido uma busca incessante por opções de plantas forrageiras onde esses problemas não ocorram.

Entre as plantas forrageiras conhecidas, existem, atualmente, alternativas compatíveis com sistemas que priorizam a exploração do mérito genético da planta forrageira (altas taxas de lotação, com desempenho animal apenas satisfatório), bem como outras destinadas a sistemas que almejam a exploração do mérito genético 
do animal (desempenho animal elevado, com modestas taxas de lotação). A gama de plantas forrageiras disponíveis é, aparentemente, suficiente para se afirmar que, salvo raras exceções, existem opções de espécies forrageiras disponíveis para os diversos tipos de ecossistemas brasileiros, assim como para quaisquer modalidades de intensificação das atividades possíveis no cenário da pecuária nacional (Lupinacci, 2003).

Grande parte das restrições à produção animal em pastagens tropicais pode ser resolvida com práticas de manejo que aumentem a eficiência de utilização ou colheita da forragem produzida. Hodgson (1985) discute quais seriam as variáveis passíveis de controle que poderiam ser utilizadas para melhorar a eficiência das práticas de manejo empregadas. Ainda segundo o autor, a utilização de variáveis arbitrárias tais como taxa de lotação, pressão de pastejo e intervalo de pastejos não podem ser consideradas como determinantes primários da produção de forragem ou do desempenho animal, uma vez que seus efeitos são mediados por características estruturais do dossel que, coletivamente, determinam a condição/estrutura do pasto ("sward state"). Essas variáveis tornam-se, então, parte de uma estratégia de ação cujo objetivo é a manutenção do pasto em condições de estrutura do dossel consideradas ideais para cumprimento de determinadas metas de desempenho e produção animal (Hodgson \& Silva, 2002).

Sob pastejo rotativo, a duração do intervalo de pastejos sucessivos - período de descanso - é o que determina a recuperação do índice de área foliar do dossel (IAF) e, consequientemente, maximiza a produção de forragem em cada ciclo de pastejo (Grant et al., 1988). Freqüientemente, a determinação do período de descanso é feita de acordo com critérios cronológicos absolutos com base no calendário juliano, como número de dias de rebrotação (Fulkerson \& Slack, 1994). Entretanto, devido a variações nas taxas de acúmulo de forragem e estacionalidade de produção, esse critério não seria o mais recomendado. Estratégias de manejo do pastejo que respeitem a fenologia e fisiologia de cada espécie forrageira podem promover aumentos na produtividade e longevidade dos pastos (Fulkerson \& Slack, 1994).

O objetivo deste trabalho foi avaliar características estruturais e produção de forragem em pastos de capimtanzânia (Panicum maximum Jacq. cv. Tanzânia) submetidos a pastejo rotativo caracterizado por combinações entre intensidades, altura de resíduo de 25 e $50 \mathrm{~cm}$, e frequiências, tempo necessário para o dossel atingir 90, 95 e 100\% de IL durante a rebrotação, de desfolhação.

\section{Material e Métodos}

A área experimental está localizada na Embrapa Gado de Corte, Campo Grande, MS (20 $27^{\circ} \mathrm{S}, 54^{\circ} 37^{\prime} \mathrm{W}$ e altitude de $530 \mathrm{~m}$ ). $\mathrm{O}$ experimento foi realizado com o capim Panicum maximum Jacq. cv. Tanzânia, estabelecido em janeiro de 1995 por meio de semeadura com $2 \mathrm{~kg}$ de sementes puras viáveis por hectare, incorporadas ao solo com gradagem leve seguida de leve compactação com rolo de pneus. O clima, segundo a classificação de Köppen, é do tipo tropical chuvoso de savana, subtipo Aw, caracterizado pela distribuição anual irregular das chuvas, com ocorrência bem definida de um período seco, durante os meses mais frios, e um período chuvoso, durante os meses de verão. Dados referentes à precipitação pluvial e temperatura média para cálculo do balanço hídrico (Figura 1) foram registrados pela estação meteorológica da Embrapa Gado de Corte, distante aproximadamente $800 \mathrm{~m}$ do local do experimento. A área experimental está assentada em um solo da classe Latossolo Vermelho distrófico (Embrapa, 1999), caracterizado por textura argilosa, $\mathrm{pH}$ ácido, baixa saturação por bases e alta concentração de alumínio. Desde agosto de 1995, a área vem sendo mantida sob pastejo.

Em relação à correção e adubação da área, no início do experimento, foram retiradas 12 amostras por piquete na profundidade de $0-10 \mathrm{~cm}$. Com base nos resultados da análise de solo, procedeu-se à fertilização da área. Foram aplicados 2,5 $\mathrm{t} \mathrm{ha}^{-1}$ de calcário dolomítico (PRNT 75\%) e $300 \mathrm{~kg} \mathrm{ha}^{-1}$ da formulação 0-20-20 (NPK). Os resultados da análise foram: saturação por bases (V), 44\%; P, 4,73 mg dm${ }^{-3}$ (Mehlich1); K, 122,1 $\mathrm{mg} \mathrm{dm}^{-3}$,

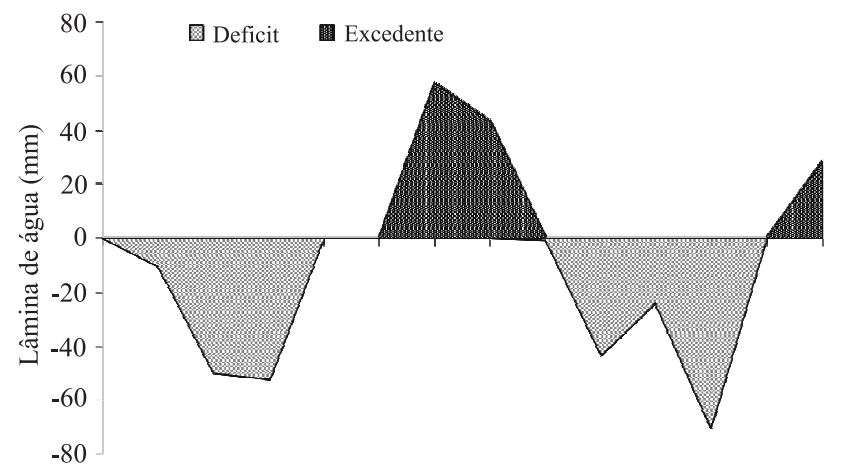

Abr. Maio Jun. Jul. Ago. Set. Out. Nov. Dez. Jan. Fev. Mar. Abr. Maio Meses

Figura 1. Balanço hídrico mensal, de abril de 2003 a maio de 2004. 
Ca, $1,74 \mathrm{cmol}_{\mathrm{c}} \mathrm{dm}^{-3} ; \mathrm{Mg}, 1,38 \mathrm{cmol}_{\mathrm{c}} \mathrm{dm}^{-3} ; \mathrm{pH}\left(\mathrm{CaCl}_{2}\right), 5,0$; capacidade de troca de cátions, $7,93 \mathrm{cmol}_{\mathrm{c}} \mathrm{dm}^{-3}$.

Os piquetes também receberam um total de $200 \mathrm{~kg} \mathrm{ha}^{-1}$ de $\mathrm{N}$ na forma de uréia. Como o intervalo entre pastejos e as condições de entrada dos animais nos piquetes eram variáveis, a quantidade de $\mathrm{N}$ aplicada e as datas de aplicação também foram variáveis, porém realizadas de forma que todos os tratamentos recebessem a mesma quantidade de $\mathrm{N}$ ao final do período experimental. Dessa forma, os tratamentos com 90 e $95 \%$ de IL, independentemente do resíduo, receberam quatro aplicações de $50 \mathrm{~kg}$ de $\mathrm{N}$. O tratamento com $100 \%$ de IL e $50 \mathrm{~cm}$ de resíduo recebeu quatro aplicações, sendo a primeira com $50 \mathrm{~kg}$, a segunda e terceira com $70 \mathrm{~kg}$ e a quarta com $10 \mathrm{~kg}$ de N. Quanto ao tratamento com $100 \%$ de IL e $25 \mathrm{~cm}$ de resíduo, recebeu três aplicações, sendo a primeira com $50 \mathrm{~kg}$, a segunda com $70 \mathrm{~kg}$ e a terceira com $80 \mathrm{~kg}$ de N.

A área utilizada no experimento encontra-se subdividida em três blocos de 1,5 ha com seis piquetes (unidades experimentais) de 0,25 ha cada, totalizando 4,5 ha. A área de reserva para a manutenção dos animais, quando estes não eram necessários para realizar os pastejos, era constituída de 3,0 ha de capim-mombaça, 3,0 ha de capimmassai e 1,5 ha de capim-tanzânia. Os tratamentos corresponderam a combinações entre três intervalos e duas intensidades de pastejo e foram alocados às unidades experimentais (piquetes) segundo um arranjo fatorial $3 \times 2$ e delineamento experimental de blocos completos ao acaso, com três repetições, totalizando 18 unidades experimentais.

Os intervalos entre pastejos corresponderam ao período de tempo necessário para que o dossel forrageiro atingisse 90,95 ou $100 \%$ de interceptação da luz incidente (IL) durante a rebrotação. As intensidades de pastejo corresponderam às alturas de resíduo de 25 e $50 \mathrm{~cm}$. A fim de facilitar a descrição, os tratamentos foram denominados da seguinte maneira: 25/90, $25 \mathrm{~cm}$ de resíduo pós-pastejo e $90 \%$ de IL no pré-pastejo; 25/95, $25 \mathrm{~cm}$ de resíduo pós-pastejo e $95 \%$ de IL no pré-pastejo; 25/100, $25 \mathrm{~cm}$ de resíduo pós-pastejo e $100 \%$ IL no pré-pastejo; $50 / 90,50 \mathrm{~cm}$ de resíduo póspastejo e $90 \%$ de IL no pré-pastejo; $50 / 95,50 \mathrm{~cm}$ de resíduo pós-pastejo e 95\% de IL no pré-pastejo; 50/100, $50 \mathrm{~cm}$ de resíduo pós-pastejo e $100 \%$ de IL no prépastejo.

O período total do experimento foi de 434 dias (8/3/2003 a 15/5/2004), com o período efetivo de coleta de dados de 11/7/2003 e 15/5/2004, totalizando 309 dias. O período de 8/3/2003 a 10/7/2003 foi destinado ao controle de plantas invasoras, coleta de amostras para análise de solo e pastejo de uniformização da área experimental.

Antes do início do experimento, a área experimental se encontrava vedada. Na primeira quinzena de março de 2003, foi realizado o rebaixamento do pasto até uma altura residual de cerca de $30 \mathrm{~cm}$. Em julho, os resíduos de 25 e $50 \mathrm{~cm}$ foram implantados em cada piquete de acordo com sorteio dos tratamentos. Foram realizadas roçadas manuais em piquetes em que a altura na área não era uniforme em torno da média. Esse procedimento foi realizado apenas no início do experimento, com o objetivo de assegurar que as metas iniciais de resíduo haviam sido geradas corretamente.

O monitoramento da interceptação de luz pelo dossel foi realizado na condição de pós-pastejo $(25$ e $50 \mathrm{~cm})$ e a intervalos de tempo variáveis durante a rebrotação para cada época do ano. No inverno, o intervalo entre avaliações foi de 15 dias para os tratamentos de $90 \%$ e 95\% de IL e 20 dias para o tratamento de $100 \%$ de IL. Nas demais épocas do ano, o intervalo foi reduzido para sete dias nos tratamentos de 90 e $95 \%$ de IL e 10 dias para os tratamentos de $100 \%$ de IL. Quando os níveis de IL estavam próximo das metas de pré-pastejo, a freqüência de monitoramento foi aumentada, com avaliações realizadas a cada três dias. Nas avaliações, foi utilizado aparelho analisador de dossel, com o qual foram realizadas leituras em seis pontos de amostragem por piquete (Carnevalli et al., 2006). Em cada ponto foram realizadas três leituras acima do dossel forrageiro e três (média de cinco leituras instantâneas) no solo.

A altura do pasto foi determinada utilizando-se régua graduada em centímetros, sendo medidos 40 pontos aleatórios por piquete. A altura de cada ponto correspondeu à altura média do dossel em torno da régua. Foram tomadas leituras de altura na condição de pré-pastejo, quando os piquetes atingiam os níveis de IL estipulados, e na condição de pós-pastejo, imediatamente depois da saída dos animais dos piquetes. O número de ciclos de pastejos e a duração de cada um deles foram monitorados durante todo o período experimental.

A massa de forragem nas condições de pré e póspastejo foi mensurada por meio do corte e pesagem de seis quadros de $1 \mathrm{~m}^{2}(1 \times 1 \mathrm{~m})$ cada por unidade experimental. Os quadros foram posicionados em pontos representativos da altura média do dossel de cada piquete no momento da amostragem e a forragem contida no interior do quadro foi cortada no nível do solo. $\mathrm{Na}$ avaliação dos componentes morfológicos da 
forragem, foi retirada uma alíquota representativa das amostras colhidas, aproximadamente $500 \mathrm{~g}$ de peso fresco, a qual foi separada nas frações lâmina foliar, colmo (colmos + bainhas) e material morto. Esses componentes foram pesados e secados em estufa de circulação forçada de ar a $60^{\circ} \mathrm{C}$ até peso constante. Os valores de massa de forragem foram convertidos para $\mathrm{kg} \mathrm{ha}^{-1}$ de matéria seca (MS) e os componentes morfológicos, expressos como proporção (\%) da massa de forragem. $\mathrm{O}$ acúmulo de forragem e de lâminas foliares $\left(\mathrm{kg} \mathrm{ha}^{-1}\right)$ foi calculado a partir da diferença entre a massa de forragem no pré-pastejo atual e no póspastejo anterior. O acúmulo total de MS do período experimental foi calculado por meio do somatório de todos os acúmulos parciais em cada ciclo de pastejo.

Nas análises estatísticas dos resultados, dados sobre as variáveis descritivas da condição do pasto, como altura de pré e pós-pastejo e o intervalo entre pastejos, apenas estatística descritiva foi utilizada, sem análise de variância. As demais variáveis foram agrupadas por época do ano - inverno, primavera, verão e outono devido à natureza variável dos intervalos e número de ciclos de pastejo nos tratamentos avaliados. Foram calculadas as médias de cada ciclo de pastejo para as seguintes variáveis: número de ciclos de pastejo, massa e componentes da forragem na condição de pré e póspastejo. Após os cálculos, os dados foram agrupados por épocas do ano e submetidos à análise de variância, utilizando-se o procedimento GLM do pacote estatístico SAS (SAS Institute, 1993). Utilizou-se o esquema de parcelas subdivididas no tempo, em que os tratamentos (Res/IL) constituíram as parcelas e as épocas do ano constituíram as subparcelas.

Os comandos RANDON e TEST foram utilizados para identificação e realização dos testes apropriados, de acordo com o delineamento especificado. Os níveis de IL foram considerados como variável discreta devido à pequena quantidade de níveis avaliados. A comparação de médias foi realizada por meio de contrastes apropriados tanto para os efeitos principais de resíduo (RES) e interceptação de luz (IL) quanto para os efeitos aninhados de RES(IL) e IL(RES), utilizando-se a probabilidade de $10 \%$.

\section{Resultados e Discussão}

O número de ciclos e os intervalos entre pastejos verificados durante todo o período experimental foram influenciados pela altura do resíduo pós-pastejo e pela interceptação de luz (IL) no pré-pastejo. Os pastos manejados a $50 \mathrm{~cm}$ de resíduo apresentaram um ciclo de pastejo a mais que os manejados a $25 \mathrm{~cm}$, conseqüência de intervalos entre pastejos mais curtos. $\mathrm{Na}$ condição de pós-pastejo, a interceptação de luz pelo dossel em pastos com $25 \mathrm{~cm}$ de resíduo foi de $50,2 \%$, enquanto nos pastos com $50 \mathrm{~cm}$ de resíduo, foi de $62,3 \%$. Essa diferença em IL no início da rebrotação foi determinante do número de ciclos de pastejo realizados.

Níveis de IL também influenciaram o número de ciclos de pastejos (Tabela 1) por causa da duração variável dos intervalos entre pastejos nos tratamentos avaliados. Durante a estação de crescimento - primavera e verão - esses intervalos médios foram de 29, 32 e 44 dias para 90, 95 e 100\% de IL, respectivamente (Figura 2). O mesmo padrão de comportamento foi descrito por Carnevalli et al. (2006) em capim-mombaça, cujo número de ciclos de pastejo foi reduzido quando a IL passou de 95 para $100 \%$.

O número de ciclos e os intervalos de pastejo referentes a cada época do ano refletiram a grande estacionalidade de produção típica do capim-tanzânia (Pedreira et al., 2005). O número de ciclos de pastejo foi 3,6 vezes superior no verão em relação ao inverno, com média de 2,2 e 0,6 ciclos, respectivamente. A velocidade de recuperação do pasto após a desfolhação depende dos fatores edafoclimáticos vigentes em um dado momento. Flutuações nas condições climáticas, resultando em estresses térmicos e hídricos, modificam a morfologia e a taxa de desenvolvimento das plantas, limitando sua produção e alterando o valor nutritivo da forragem produzida (Buxton \& Fales, 1994).

Nas estações de crescimento em que ocorreram condições climáticas favoráveis (temperatura, radiação e água), a velocidade de recuperação do pasto foi mais rápida, reduzindo intervalos entre pastejos e aumentando, assim, o número de ciclos de pastejo ao final do

Tabela 1. Número total de ciclos de pastejo durante o período experimental para o capim-tanzânia submetido a combinações entre intensidade e frequiência de desfolhação ${ }^{(1)}$.

\begin{tabular}{lccc}
\hline Resíduo (cm) & \multicolumn{3}{c}{ Interceptação luminosa (\%) } \\
\cline { 2 - 4 } & 90 & 95 & 100 \\
\hline 25 & $6,0 \mathrm{bA}$ & $5,0 \mathrm{bB}$ & $3,0 \mathrm{bC}$ \\
50 & $7,0 \mathrm{aA}$ & $6,0 \mathrm{aB}$ & $4,0 \mathrm{aC}$ \\
\hline
\end{tabular}

${ }^{(1)}$ Médias seguidas de mesma letra minúscula, na coluna, não diferem entre si pelo teste $\mathrm{F}$, a $10 \%$ de probabilidade; médias seguidas de mesma letra maiúscula, na linha, não diferem entre si pelo teste t, a 10\% de probabilidade. 
experimento. De acordo com Uebele (2002), a inferência prática desses resultados é simples, ou seja, estratégias de manejo do pastejo baseadas em períodos de descanso fixos são potencialmente perigosas, podendo resultar em perdas significativas de produção e valor nutritivo da forragem produzida. A mesma autora demonstrou padrão de comportamento semelhante para o capimmombaça, quando submetido a tratamentos definidos por combinações entre resíduos de 30 e 50 cm e 95 e $100 \%$ de IL como critérios para o manejo do pastejo.
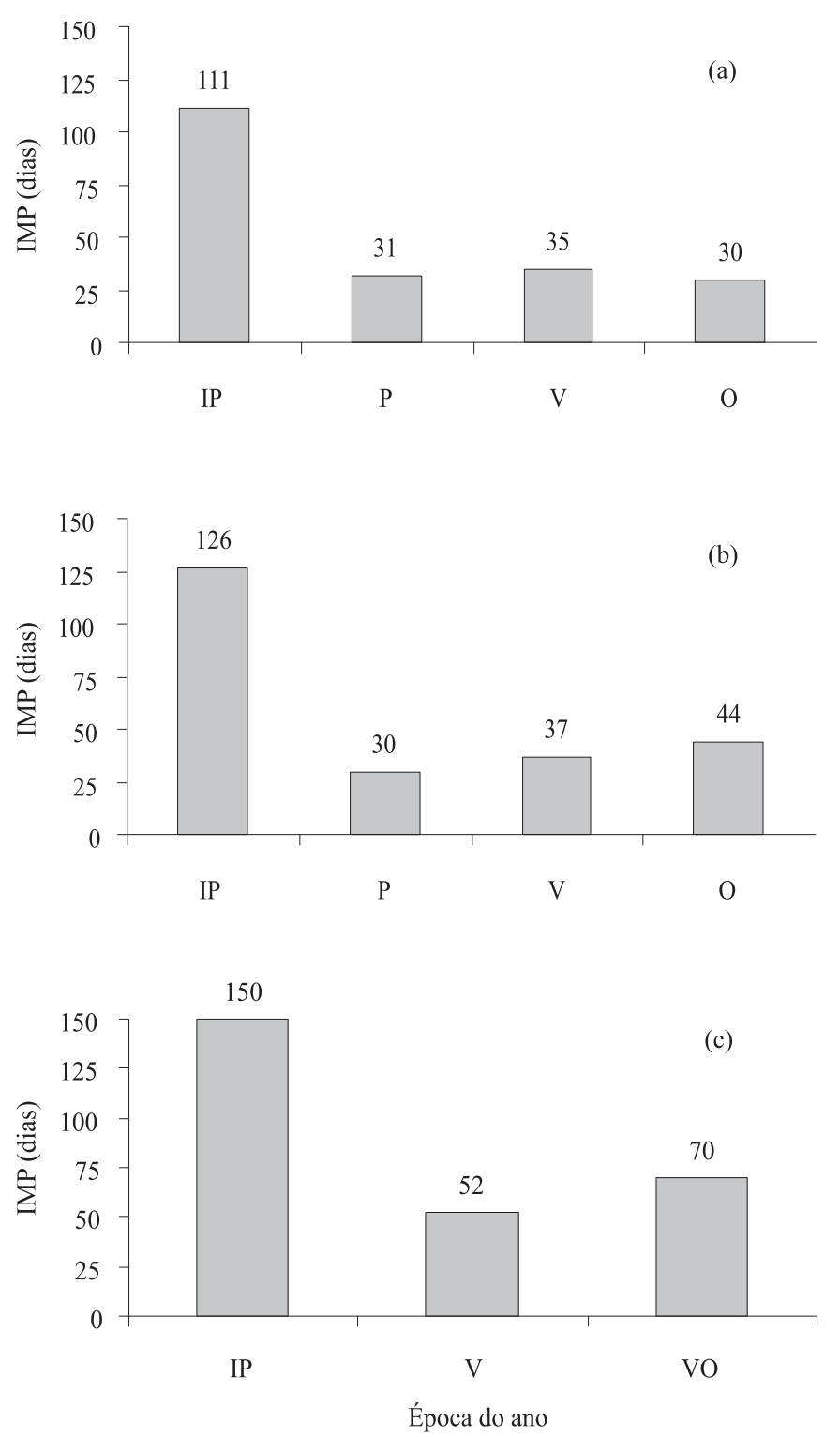

A manutenção da altura de resíduo de $50 \mathrm{~cm}$ foi alcançada satisfatoriamente, independentemente do nível de IL praticado (Figura 3). Mesmo durante o período reprodutivo, época em que ocorreu pronunciado alongamento de colmos, foi possível manter o resíduo em $50 \mathrm{~cm}$ para todos os níveis de IL. Em contrapartida, nos tratamentos de $25 \mathrm{~cm}$ de resíduo, não foi possível manter a altura estipulada, exceção feita aos tratamentos de $90 \%$ de IL. Com a sucessão de ciclos de pastejo, os pastos manejados a $95 \%$ e, especialmente, $100 \%$ de IL,
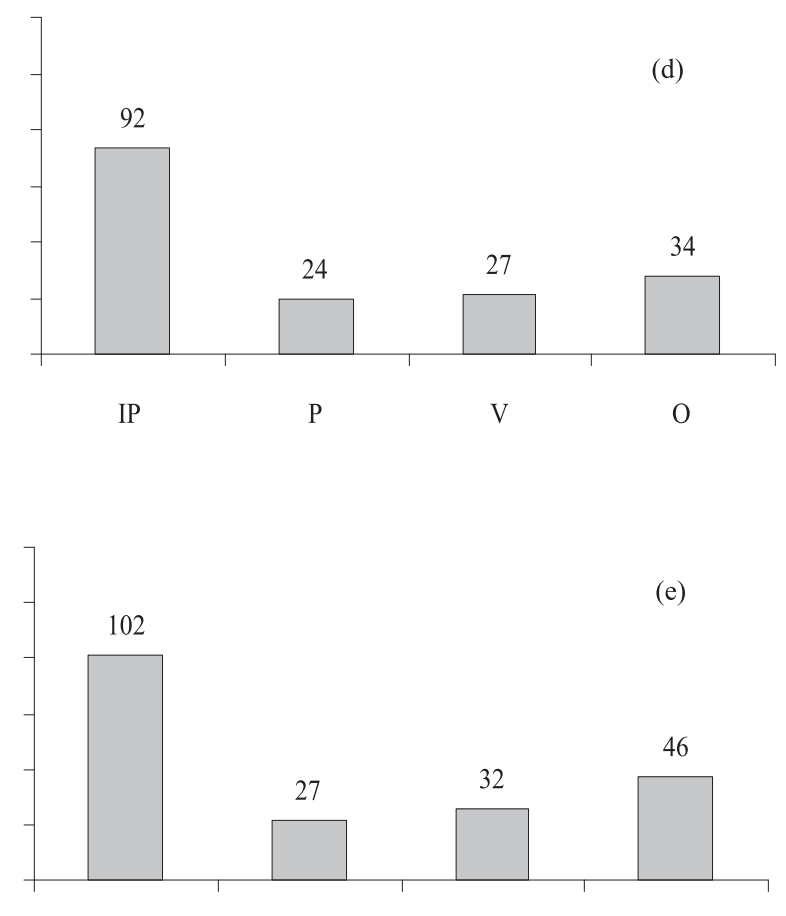

IP

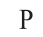

$\mathrm{O}$

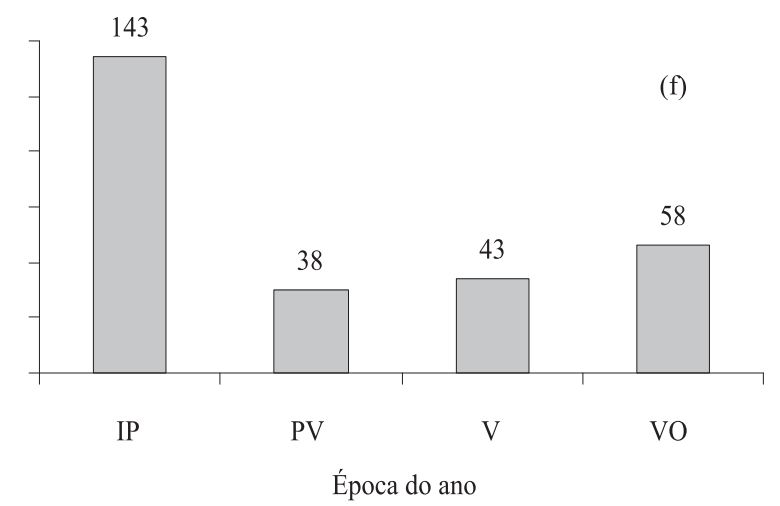

IP, transição entre inverno e primavera; P, primavera; V, verão; $\mathrm{O}$, outono; VO, transição entre verão e outono

Figura 2. Intervalo médio de pastejos (IMP) para os tratamentos de $25 \mathrm{~cm}$ de resíduo e interceptação luminosa (IL) de 90 (a), 95 (b) e $100 \%$ (c) e 50 cm de resíduo e IL de 90 (d), 95 (e) e 100\% (f) durante as épocas do ano. 
apresentaram altura de resíduo aumentada (Figura 3). Esse comportamento foi marcante para o tratamento 25/100, cuja altura do resíduo, no início do experimento, era de $27 \mathrm{~cm}$ e, no último ciclo de pastejo, chegou a $40 \mathrm{~cm}$. De fato, o último ciclo de pastejo ocorreu durante
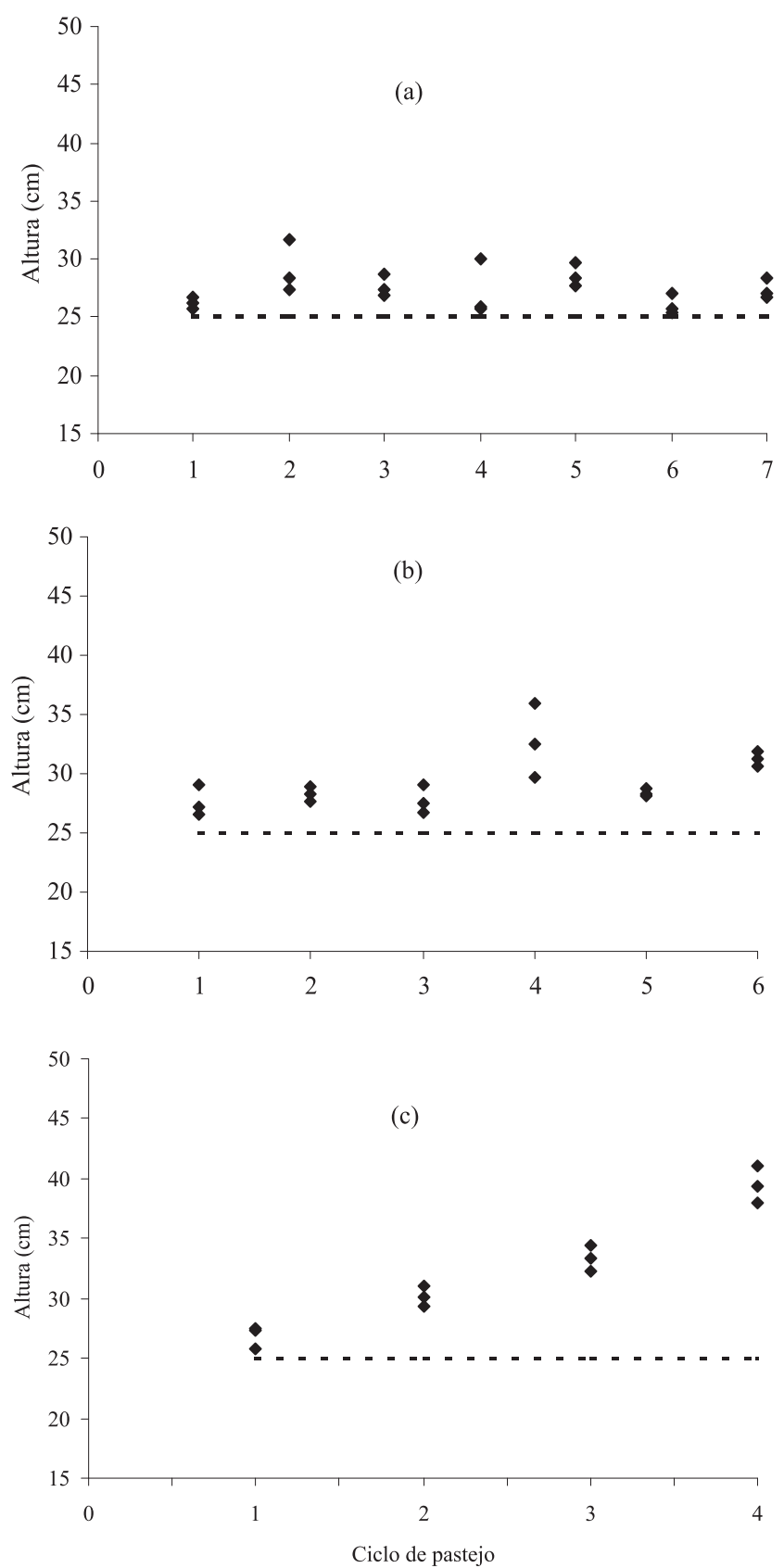

o período de outono, época de florescimento intenso das plantas, em que o alongamento de colmos foi acentuado, ocasionando dificuldade de rebaixamento do pasto. De forma semelhante, Uebele (2002) não conseguiu manter a altura de resíduo de $30 \mathrm{~cm}$ em relação à meta
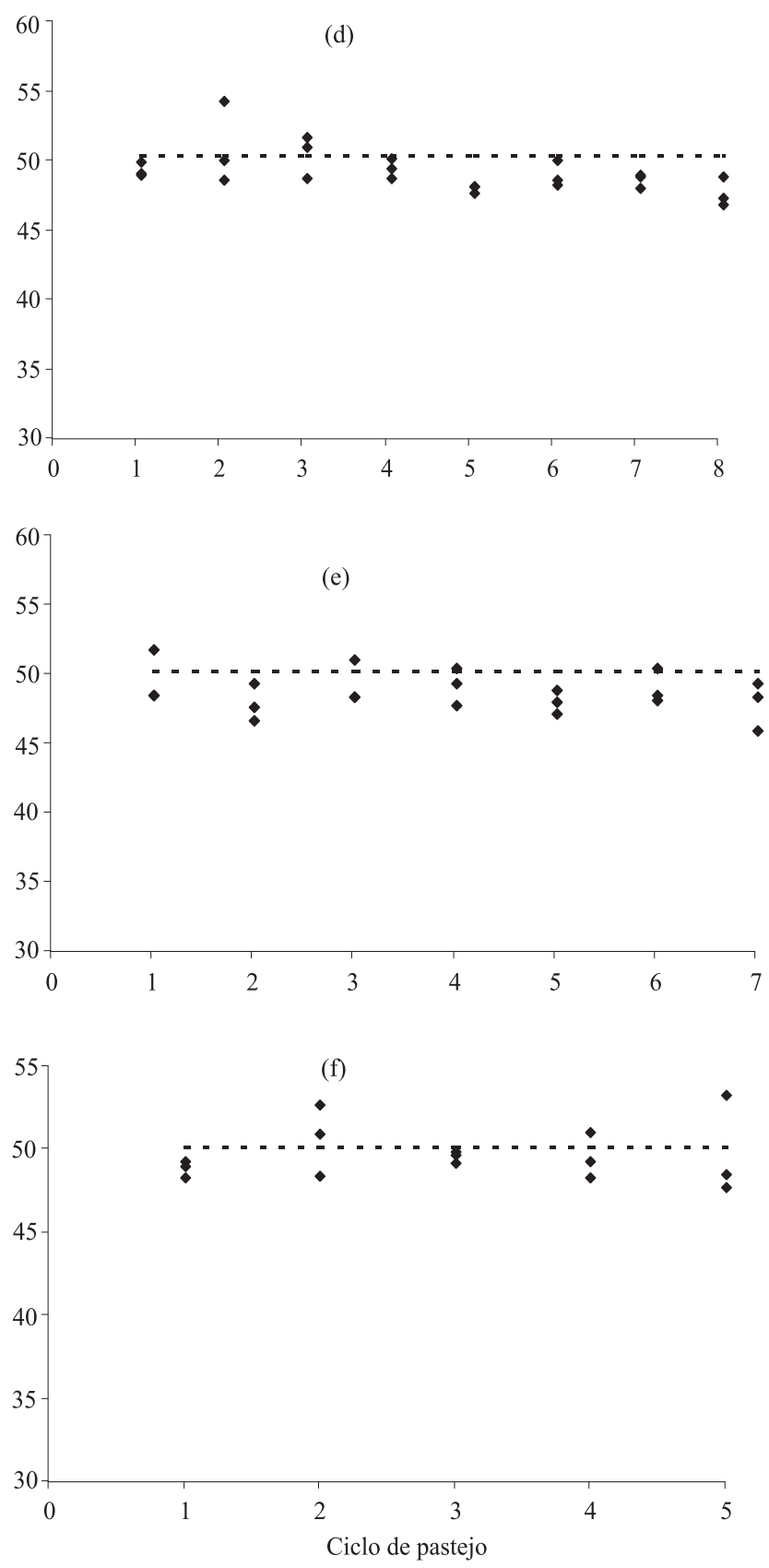

Observado

-..- Pretendido

Figura 3. Altura média do dossel do capim-tanzânia na condição de pós-pastejo para os tratamentos com 90 (a), 95 (b) e $100 \%$ (c) de interceptação luminosa (IL) e altura pretendida de $25 \mathrm{~cm}$ de resíduo e para os tratamentos com 90 (d), 95 (e) e $100 \%$ (f) de IL e altura pretendida de $50 \mathrm{~cm}$ de resíduo. 
de $50 \mathrm{~cm}$, quando foram empregados períodos de descanso mais longos (100\% de IL para início do pastejo).

A altura do dossel em pré-pastejo comportou-se de forma homogênea durante todo o período experimental. Independentemente do resíduo considerado, as alturas de pré-pastejo estiveram em torno de 60,70 e $85 \mathrm{~cm}$
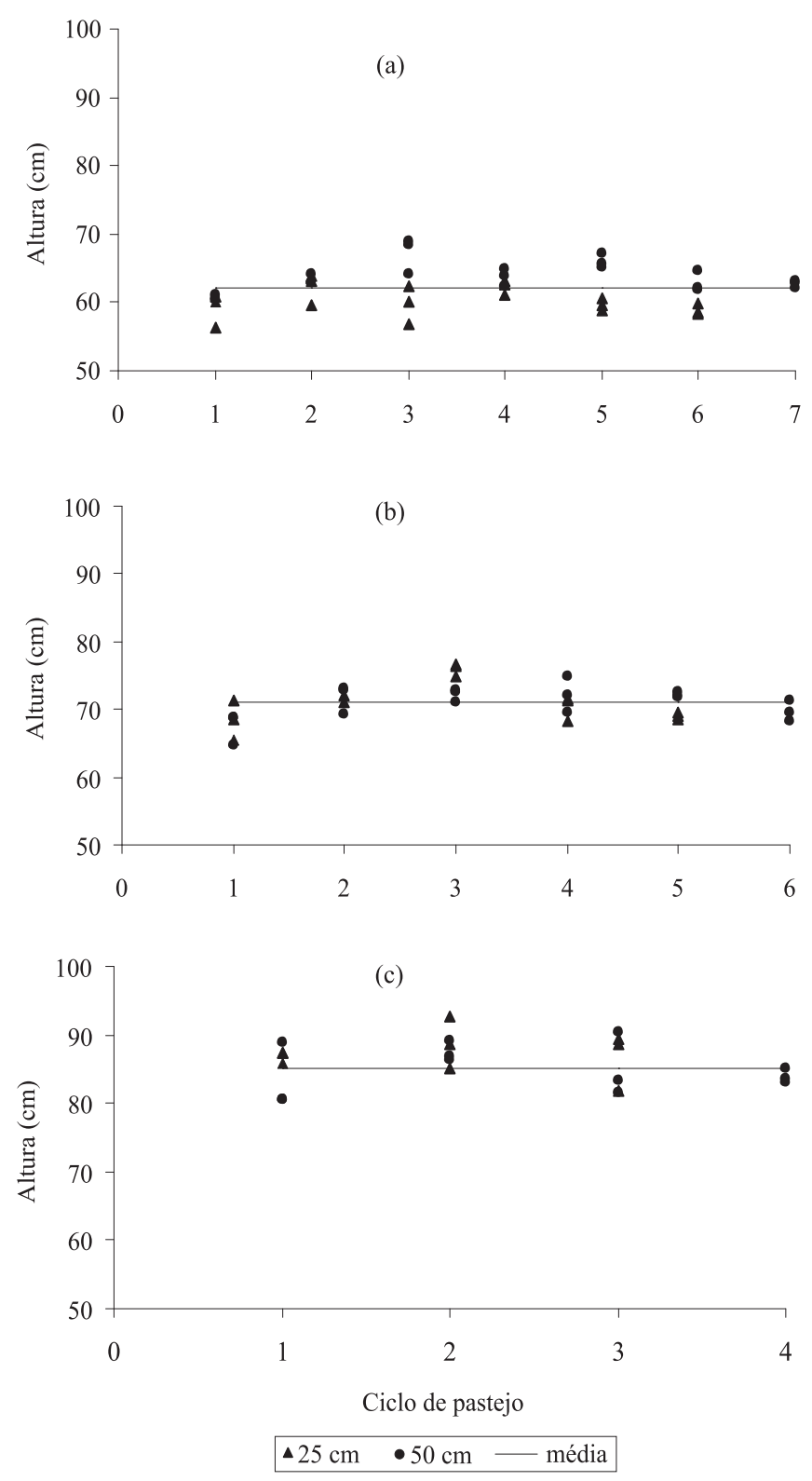

Figura 4. Altura do dossel de capim-tanzânia, na condição de pré-pastejo, durante o ano, em função dos níveis de interceptação luminosa (IL) e resíduo pós-pastejo. Letras a, b e c correspondem a 90, 95 e $100 \%$ de IL, respectivamente. para os tratamentos de 90, 95 e 100\% de IL (Figura 4), respectivamente. Maiores alturas de pré-pastejo para os tratamentos de $100 \%$ de IL foram resultado de intervalos entre pastejos mais longos (Figura 2) e de maior acúmulo de colmos (Barbosa, 2004). Foram detectadas pequenas variações na altura dos tratamentos de $90 \%$ de IL, com tendência de redução na altura de pré-pastejo, quando associados ao resíduo de $25 \mathrm{~cm}$.

Como o nível de interceptação de luz pelo dossel é uma variável difícil de ser avaliada e monitorada, em condições práticas de campo, a altura do dossel forrageiro no prépastejo mostrou-se bom parâmetro, uma vez que apresentou associação positiva e consistente com os valores de IL mensurados. Essa associação positiva entre altura e IL, na condição de pré-pastejo, é bem descrita e documentada em gramíneas de clima temperado (Hodgson, 1990), tendo sido verificada também em gramíneas tropicais tais como o capim-mombaça (Carnevalli et al., 2006) e o capim-tanzânia (Mello, 2002). Se em um determinado nível de IL, a altura de pré-pastejo se mantém relativamente constante, a variação em altura do resíduo poderá possibilitar ajustes e alterações nos intervalos de pastejos, eficiência de colheita da forragem produzida, nível de desempenho animal a ser obtido, além de permitir ajustes relativos à fertilidade do solo da área, onde se trabalha e, ou política de uso de corretivos e fertilizantes utilizados (Silva, 2004).

A massa de forragem, assim como a altura do dossel na condição de pré-pastejo, aumentou de acordo com o incremento nos níveis de IL. Maiores valores de massa de forragem foram verificados nos tratamentos de 100\% de IL (Tabela 2). Estes, apesar de apresentarem maior massa de forragem no início do pastejo, apresentaram grande quantidade de material morto e colmo na sua composição, principalmente no caso do resíduo de $50 \mathrm{~cm}$ (Figura 5). Os tratamentos de $90 \%$ de IL foram os que apresentaram a menor massa de forragem no pré-pastejo (Tabela 2). Entretanto, apresentaram a menor produção de colmos durante todo o período de avaliação (Figura 5). Os elevados valores de massa de forragem por ciclo de pastejo para os tratamentos de $100 \%$ de IL não implicaram necessariamente que estes fossem os mais produtivos, uma vez que foram obtidos à custa de longos períodos de descanso (Figura 2), que reduziram o número de ciclos de pastejo realizados durante o período experimental (Tabela 1). Adicionalmente, as alterações em estrutura do dossel forrageiro em função do elevado alongamento de colmos (Barbosa, 2004) e a grande quantidade de material morto acumulada no perfil do 
dossel (Figura 5) ratificam as limitações do uso de períodos de descanso excessivamente longos, relativamente ao ideal necessário para a recuperação e restabelecimento da área foliar do dossel após o pastejo.

A altura do resíduo alterou a massa de forragem no pré-pastejo somente durante o outono, e nas demais épocas do ano este efeito não foi verificado. Os pastos manejados com $50 \mathrm{~cm}$ de resíduo apresentaram, em média, 1,0 tha $\mathrm{th}^{-1} \mathrm{de} \mathrm{MS}$ a mais que os manejados com $25 \mathrm{~cm}$ de resíduo, sendo as médias de 5.810 e $4.890 \mathrm{~kg} \mathrm{ha}^{-1}$ de MS, respectivamente. Entretanto, a análise dos componentes da forragem dos pastos manejados com $50 \mathrm{~cm}$ de resíduo indicou pequena contribuição de lâminas foliares e elevadas proporções de colmo e material morto na massa de forragem sob aquelas circunstâncias (Figura 5).

Pastos manejados com $25 \mathrm{~cm}$ de resíduo apresentaram os menores valores de massa de forragem no pós-pastejo, independentemente da época do ano (Tabela 2). Além disso, apresentaram, também, as menores porcentagens de lâminas foliares remanescentes e elevadas porcentagens de material morto (Figura 6). Durante a primavera e verão/outono, pastos manejados com $50 \mathrm{~cm}$ de resíduo apresentaram maior proporção de lâminas foliares e menor proporção de colmos e material morto na massa de forragem em pós-pastejo (Figura 6). A manutenção de um resíduo alto implica menor remoção de forragem pelos animais. Dessa forma, é compreensível o fato de que os tratamentos de $50 \mathrm{~cm}$ de resíduo tenham apresentado maiores porcentagens de lâminas foliares, quando comparados aos tratamentos de $25 \mathrm{~cm}$ de resíduo. Com relação às freqüências de desfolhação, pastos em que os pastejos foram realizados com 90 e $95 \%$ de IL apresentaram comportamento bastante homogêneo durante as épocas do ano. Por sua vez, nos pastos em que os pastejos foram realizados de maneira menos frequiente ( $100 \%$ de IL), a massa de forragem pós-pastejo foi maior e caracterizada por elevada participação de colmos (Figura 6).

Foram registradas maiores porcentagens de material morto durante o inverno e elevada participação de colmos na massa de forragem em pós-pastejo durante o verão/ outono. Por sua vez, o componente com maior participação na massa de forragem em pós-pastejo foi o material morto, seguido de colmos e lâminas foliares. Durante a primavera, o tratamento $25 / 90$ foi o que apresentou a maior porcentagem de lâminas foliares no resíduo pós-pastejo. Pastejos mais intensos e freqüentes, associados a uma renovação na população de perfilhos durante a transição entre o inverno e a primavera (Barbosa, 2004), promoveram controle efetivo do desenvolvimento de colmos, o que propiciou maior presença de lâminas foliares na massa de forragem residual.

Maior acúmulo de forragem foi registrado no tratamento 25/95 e o menor no 50/90 (Tabela 3). Os demais tratamentos apresentaram comportamento intermediário, não diferindo entre si. A maior quantidade de forragem acumulada para o tratamento 25/95 foi resultado das altas taxas de acúmulo durante o verão. O tratamento 50/90, apesar do maior número de ciclos de pastejo realizados, apresentou menor acúmulo de MS total durante o período experimental. Os menores acúmulos por época do ano (Tabela 4) e a elevação da massa de forragem, no pós-pastejo durante o período de verão/outono (Tabela 2 ), foram determinantes do menor acúmulo de forragem desse tratamento. Os tratamentos com $90 \%$ de IL apresentaram menor acúmulo de forragem devido à menor quantidade de folhas para aproveitamento da radiação incidente, implicando limitações no processo de crescimento.

Tabela 2. Matéria seca de forragem $\left(\mathrm{kg} \mathrm{ha}^{-1}\right)$ na condição de pré e pós-pastejo do capim-tanzânia submetido a combinações de intensidade e frequiência de desfolhação durante as épocas do ano ${ }^{(1)}$.

\begin{tabular}{|c|c|c|c|c|c|c|}
\hline \multirow{2}{*}{$\begin{array}{l}\text { Resíduo } \\
\text { (cm) }\end{array}$} & \multicolumn{3}{|c|}{ Pré-pastejo } & \multicolumn{3}{|c|}{ Pós-pastejo } \\
\hline & $90 \%$ & $95 \%$ & $100 \%$ & $90 \%$ & $95 \%$ & $100 \%$ \\
\hline & \multicolumn{3}{|c|}{---- Inverno/primavera (EPM = 296) ------ } & \multicolumn{3}{|c|}{ - Inverno (EPM = 156) - } \\
\hline 25 & $4.070 \mathrm{aC}$ & $4.880 \mathrm{aB}$ & $6.650 \mathrm{aA}$ & $2.190 \mathrm{bB}$ & $2.150 \mathrm{bB}$ & $2.760 \mathrm{aA}$ \\
\hline \multirow[t]{2}{*}{50} & $4.490 \mathrm{aB}$ & $5.100 \mathrm{aB}$ & $6.620 \mathrm{aA}$ & $2.930 \mathrm{aA}$ & $2.980 \mathrm{aA}$ & $3.130 \mathrm{aA}$ \\
\hline & \multicolumn{3}{|c|}{ 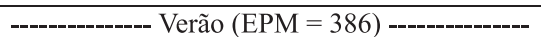 } & \multicolumn{3}{|c|}{------------ Primavera (EPM = 227) ----------- } \\
\hline 25 & $4.540 \mathrm{aC}$ & $5.540 \mathrm{aB}$ & $7.040 \mathrm{aA}$ & $2.130 \mathrm{bB}$ & $2.000 \mathrm{bB}$ & $2.930 \mathrm{bA}$ \\
\hline \multirow[t]{2}{*}{50} & $4.900 \mathrm{aB}$ & $5.460 \mathrm{aB}$ & $7.490 \mathrm{aA}$ & $3.240 \mathrm{aB}$ & $3.470 \mathrm{aB}$ & $4.100 \mathrm{aA}$ \\
\hline & \multicolumn{3}{|c|}{ 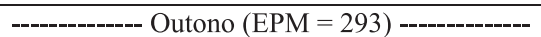 } & \multicolumn{3}{|c|}{ 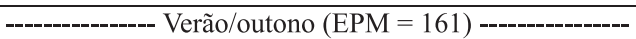 } \\
\hline 25 & $3.650 \mathrm{aC}$ & $5.050 \mathrm{bB}$ & $5.970 \mathrm{bA}$ & $2.410 \mathrm{bA}$ & $2.160 \mathrm{bA}$ & $2.220 \mathrm{bA}$ \\
\hline 50 & $4.220 \mathrm{aB}$ & $6.230 \mathrm{aA}$ & $6.970 \mathrm{aA}$ & $4.000 \mathrm{bAB}$ & $3.900 \mathrm{bB}$ & $4.300 \mathrm{aA}$ \\
\hline
\end{tabular}

(1)Médias com mesma letra minúscula na coluna, dentro de época e condição de pastejo, não diferem entre si pelo teste F, a 10\% de probabilidade; médias com mesma letra maiúscula na linha, dentro de época e condição de pastejo, não diferem entre si pelo teste $t$ a $10 \%$ de probabilidade; EPM: erro-padrão da média da interação Res x interceptação luminosa. 
Quanto aos tratamentos de 100\% de IL, acabaram sendo prejudicados pelo excesso de material morto presente no perfil do dossel, principalmente no tratamento 50/100.

Em relação aos resíduos, maior acúmulo de forragem foi registrado nos tratamentos de $25 \mathrm{~cm}$ de resíduo, em relação àqueles de $50 \mathrm{~cm}$. A maior proporção de folhas remanescentes do resíduo de $50 \mathrm{~cm}$ contribuiu para que
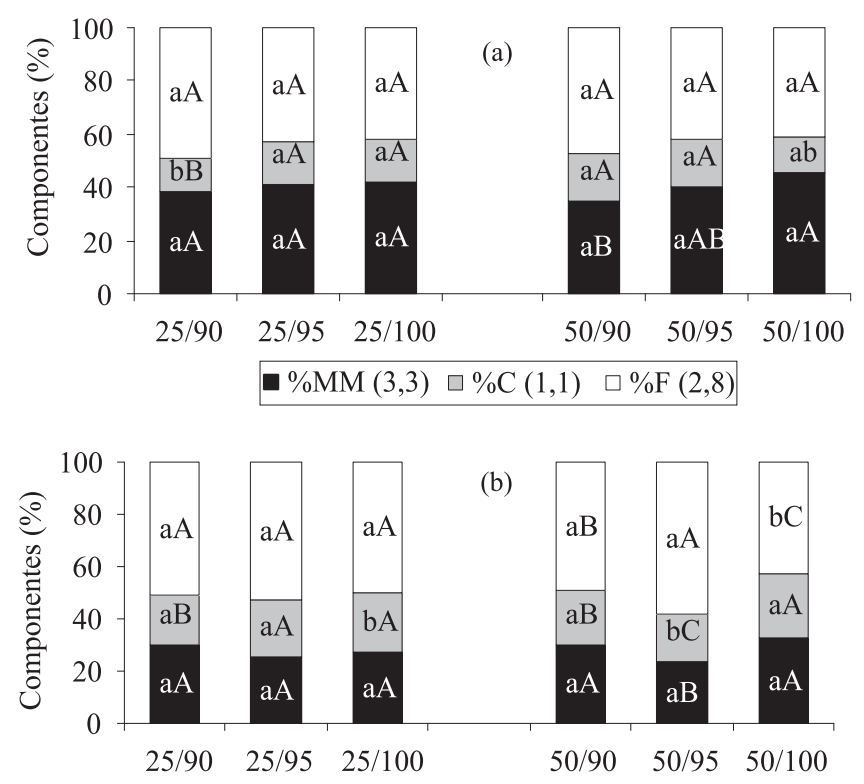

口 \%MM (2,2) $\square \% \mathrm{C}(1,2) \quad \square \% \mathrm{~F}(2,4)$

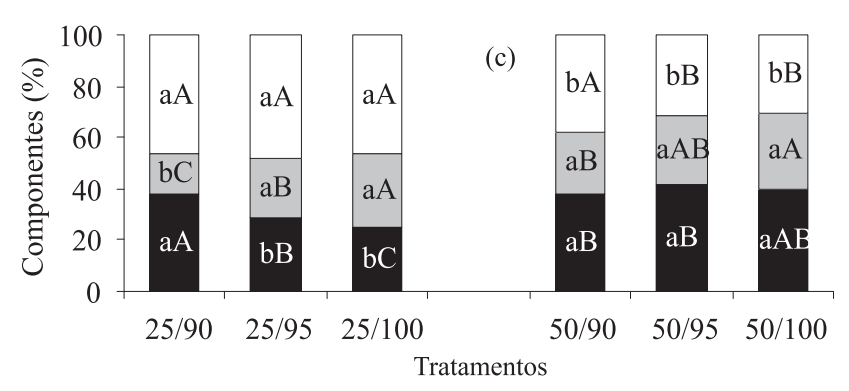

a \%M (1,3) $\square \% \mathrm{C}(1,8) \quad \square \% \mathrm{~F}(2,3)$

Figura 5. Componentes da forragem (MM, material morto; C, colmo; F, folha) em pré-pastejo do capim-tanzânia submetido a combinações de intensidade e freqüência de desfolhação durante as épocas do ano, sendo inverno/primavera (a), verão (b) e outono (c). Letras minúsculas comparam resíduos em cada nível de interceptação luminosa (IL), dentro de épocas do ano, para cada componente da forragem, pelo teste $\mathrm{F}$, a $10 \%$ de probabilidade. Letras maiúsculas comparam níveis de IL em cada resíduo, dentro de épocas do ano, para cada componente da forragem, pelo teste $\mathrm{t}$, a $10 \%$ de probabilidade. Valores entre parênteses, nas legendas, se referem ao erro-padrão da média de cada componente da forragem. a meta de pré-pastejo (níveis de IL) fosse alcançada mais rapidamente (Figura 2), aumentando, assim, o número de ciclos de pastejo (Tabela 1). Entretanto, nesse caso, o maior número de ciclos de pastejo não foi suficiente para compensar a menor produção por ciclo e o elevado acúmulo de MS dos tratamentos de resíduo $25 \mathrm{~cm}$, principalmente durante o verão e o outono.
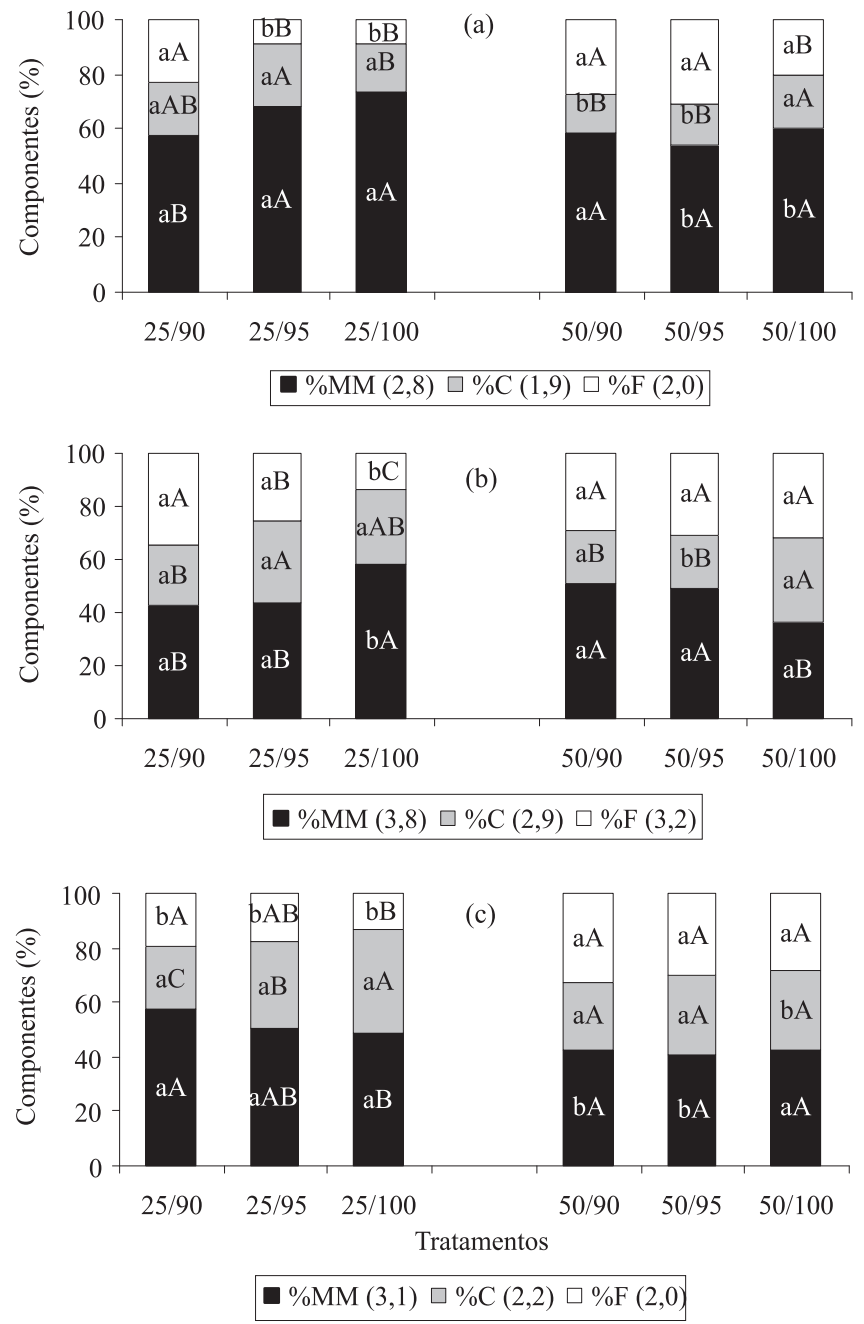

Figura 6. Componentes da forragem (MM, material morto; $\mathrm{C}$, colmo; F, folha) em pós-pastejo do capim-tanzânia submetido a combinações de intensidade e freqüência de desfolhação durante as épocas do ano, sendo inverno (a), primavera (b) e verão/outono (c). Letras minúsculas comparam resíduos em cada nível de interceptação luminosa (IL), dentro de épocas do ano, para cada componente da forragem, pelo teste $\mathrm{F}$, a $10 \%$ de probabilidade. Letras maiúsculas comparam níveis de IL em cada resíduo, dentro de épocas do ano, para cada componente da forragem, pelo teste t, a $10 \%$ de probabilidade. Valores entre parênteses, nas legendas, se referem ao erro-padrão da média de cada componente. 
Um fato importante a ser ressaltado é que, quando são consideradas as taxas de acúmulo de lâminas foliares verdes, os tratamentos de 90 e $95 \%$ de IL não diferiram entre si, porém foram superiores aos tratamentos de $100 \%$ de IL (Tabela 3). Assim, desfolhações mais intensas $(25 \mathrm{~cm})$ e freqüentes $(90 \%$ e $95 \%$ de IL) promoveram intenso aparecimento de perfilhos novos, aumentando sua densidade populacional (Barbosa, 2004). Adicionalmente, esses perfilhos novos apresentaram taxas de alongamento e aparecimento de folhas superiores a perfilhos maduros e velhos (Barbosa, 2004). Este fato favoreceu as estratégias de desfolhação que propiciaram a geração de populações de perfilhos de perfil mais jovem. Outro ponto importante reside no fato de que, nos tratamentos de $90 \%$ de IL, em média, $82 \%$ da forragem acumulada 95 e $100 \%$ de IL, houve decréscimo da ordem de 15 e $23 \%$ da fração lâmina foliar, respectivamente, em relação ao tratamento de $90 \%$ de IL.

Tabela 3. Acúmulo de matéria seca (MS) e de lâminas foliares $\left(\mathrm{kg} \mathrm{ha}^{-1}\right)$ do capim-tanzânia submetido a combinações de intensidade e freqüência de desfolhação durante o período experimental $^{(1)}$.

\begin{tabular}{cccccccc}
\hline \multirow{2}{*}{$\begin{array}{c}\text { Resíduo } \\
(\mathrm{cm})\end{array}$} & \multicolumn{3}{c}{ MS total } & & \multicolumn{3}{c}{ MS de lâminas foliares } \\
\cline { 2 - 4 } \cline { 6 - 7 } & $90 \%$ & $95 \%$ & $100 \%$ & & $90 \%$ & $95 \%$ & $100 \%$ \\
\hline 25 & $11.740 \mathrm{aB}$ & $15.120 \mathrm{aA}$ & $11.620 \mathrm{aB}$ & & $9.000 \mathrm{aB}$ & $10.560 \mathrm{aA}$ & $8.030 \mathrm{aB}$ \\
50 & $9.440 \mathrm{bB}$ & $11.940 \mathrm{bA}$ & $12.710 \mathrm{aA}$ & & $8.360 \mathrm{aA}$ & $8.060 \mathrm{bA}$ & $6.750 \mathrm{bB}$ \\
\hline
\end{tabular}

(1) Médias seguidas de mesma letra minúscula na linha, para cada componente, não diferem entre si pelo teste t, a $10 \%$ de probabilidade; médias seguidas de mesma letra maiúscula na coluna, para cada componente, não diferem entre si pelo teste $\mathrm{F}$, a $10 \%$ de probabilidade; erro-padrão da média do Res x acúmulo de MS igual a 770 e $392 \mathrm{~kg} \mathrm{ha}^{-1}$, para MS total e MS de lâminas foliares, respectivamente.
Tanto o acúmulo de forragem total como o de lâminas verdes apresentaram comportamento sazonal entre as épocas do ano (Tabela 4). Maiores acúmulos de forragem e de lâminas foliares foram registrados durante as épocas de maior disponibilidade de fatores de crescimento (e.g., luz, temperatura, água), principalmente no verão, com valores da ordem de 67 e $48 \mathrm{~kg} \mathrm{ha}^{-1} \mathrm{dia}^{-1}$ para MS total e de lâminas foliares, respectivamente. Nessa época, o tratamento 25/95 foi o com maior acúmulo de forragem e de lâminas. Durante o inverno, o acúmulo de MS total e de lâminas foliares foi bastante reduzido, tendo sido registrados valores de 21 e $14 \mathrm{~kg} \mathrm{ha}^{-1} \mathrm{dia}^{-1} \mathrm{de}$ MS, respectivamente. As baixas taxas de acúmulo verificadas durante a primavera para o tratamento $25 / 100$ foram consequiência do longo ciclo de pastejo realizado na transição inverno/ primavera. Esse padrão sazonal também foi verificado por Pedreira et al. (2005), em capim-tanzânia sob lotação intermitente, porém com valores bem superiores, em termos de taxa de acúmulo de forragem, durante a estação chuvosa (121 kg ha-1 dia $^{-1}$ de MS) e aplicação de $250 \mathrm{~kg} \mathrm{ha}^{-1}$ ano $^{-1}$ de nitrogênio.

Taxas de acúmulo de MS total e de lâminas foliares apresentaram relações diferentes quando analisadas em termos de frequiência de pastejo durante o período experimental. Nos tratamentos de $90 \%$ de IL, as taxas de acúmulo de MS de lâminas foliares apresentaram diferença de apenas $18 \%$ em relação às taxas de

Tabela 4. Acúmulo de matéria seca (MS) total e de lâminas foliares $\left(\mathrm{kg} \mathrm{ha}^{-1}\right)$ do capim-tanzânia em combinações de intensidade e frequiência de desfolhação durante as épocas do ano ${ }^{(1)}$.

\begin{tabular}{|c|c|c|c|c|c|c|}
\hline \multirow[t]{2}{*}{ Resíduo $(\mathrm{cm})$} & \multicolumn{3}{|c|}{ MS total } & \multicolumn{3}{|c|}{ MS de lâminas foliares } \\
\hline & $90 \%$ & $95 \%$ & $100 \%$ & $90 \%$ & $95 \%$ & $100 \%$ \\
\hline & \multicolumn{3}{|c|}{--o---- Inverno (EPM = 395) - } & \multicolumn{3}{|c|}{-------------- Inverno (EPM = 170) ----------- } \\
\hline 25 & $1.230 \mathrm{aA}$ & $1.510 \mathrm{aA}$ & $1.920 \mathrm{aA}$ & $900 \mathrm{aB}$ & $1.380 \mathrm{aA}$ & $1.250 \mathrm{aAB}$ \\
\hline 50 & $970 \mathrm{aA}$ & $1.620 \mathrm{aA}$ & $1.740 \mathrm{aA}$ & $890 \mathrm{aA}$ & $720 \mathrm{bA}$ & $1.040 \mathrm{aA}$ \\
\hline & \multicolumn{3}{|c|}{-------------- Primavera $(\mathrm{EPM}=420)$-------------- } & \multicolumn{3}{|c|}{ 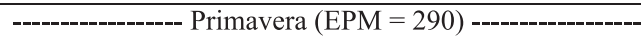 } \\
\hline 25 & $3.130 \mathrm{aA}$ & $3.780 \mathrm{aA}$ & $1.970 \mathrm{aB}$ & $2.950 \mathrm{aA}$ & $2.380 \mathrm{aA}$ & $1.290 \mathrm{aB}$ \\
\hline \multirow{2}{*}{50} & $3.570 \mathrm{aAB}$ & $4.000 \mathrm{aA}$ & $2.810 \mathrm{aB}$ & $3.200 \mathrm{aA}$ & $2.660 \mathrm{aA}$ & $1.910 \mathrm{aB}$ \\
\hline & \multicolumn{3}{|c|}{----------- Verão $($ EPM = 750) ----------- } & \multicolumn{3}{|c|}{ 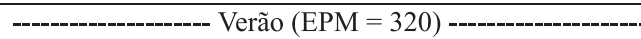 } \\
\hline 25 & $4.380 \mathrm{aB}$ & $7.000 \mathrm{aA}$ & $5.720 \mathrm{aAB}$ & $3.590 \mathrm{aB}$ & $4.860 \mathrm{aA}$ & $4.130 \mathrm{aAB}$ \\
\hline 50 & $4.210 \mathrm{aB}$ & $4.820 \mathrm{bAB}$ & $6.400 \mathrm{aA}$ & $3.690 \mathrm{aAB}$ & $3.940 \mathrm{bA}$ & $3.110 \mathrm{bB}$ \\
\hline & \multicolumn{3}{|c|}{---o- Outono (EPM = 265) --- } & \multicolumn{3}{|c|}{ - Outono $(\mathrm{EPM}=180)$} \\
\hline 25 & $3.000 \mathrm{aA}$ & $2.810 \mathrm{aA}$ & $2.020 \mathrm{aB}$ & $1.930 \mathrm{aA}$ & $1.970 \mathrm{aA}$ & $1.350 \mathrm{aB}$ \\
\hline 50 & $680 \mathrm{bB}$ & $1.480 \mathrm{bA}$ & $1.750 \mathrm{aA}$ & $570 \mathrm{bA}$ & $730 \mathrm{bA}$ & $680 \mathrm{bA}$ \\
\hline
\end{tabular}

(1)Médias com mesma letra minúscula na coluna, dentro de época e componente, não diferem entre si pelo teste F, a $10 \%$ de probabilidade; médias com mesma letra maiúscula na linha, dentro de época e componente, não diferem entre si pelo teste t, a 10\% de probabilidade; EPM: erro-padrão da média da interação Res x interceptação luminosa. 
acúmulo total de forragem. Quando analisados os tratamentos de 95 e $100 \%$ de IL, foi verificado que essa diferença passou para 35 e $40 \%$, respectivamente.

Longos períodos de descanso resultaram em alterações indesejáveis da estrutura do dossel forrageiro, caracterizadas pela elevação da participação de colmos e de material morto no perfil do dossel. Esse fato pode resultar em perdas de forragem por ação do pastejo, tanto pela quantidade de material indesejado quanto por danos físicos provocados pelos animais (Carnevalli et al., 2006), influenciando negativamente a eficiência de colheita (Carnevalli et al., 2006) e o valor nutritivo (Bueno, 2003) do material produzido.

As variações observadas no acúmulo de MS total e de lâminas foliares em função das épocas do anoparecem indicar que nenhuma das combinações entre RES e IL foi consistentemente superior (Tabela 4). Uma das razões reside no fato de que o número de ciclos de pastejo em cada época do ano foi variável em função das combinações de RES e IL, implicando políticas de fertilização dos pastos variadas, que alteraram a dinâmica de acúmulo de forragem ao longo do tempo. No entanto, quando se analisa o total acumulado, principalmente de lâminas foliares (Tabela 3), é demon0strado que, na média, os tratamentos com $95 \%$ de IL foram superiores aos demais, assim como o resíduo de $25 \mathrm{~cm}$ foi superior ao de $50 \mathrm{~cm}$.

\section{Conclusões}

1. A altura do dossel do capim-tanzânia se apresenta estável em relação a interceptação de luz de 90, 95 e $100 \%$.

2. Longos períodos de descanso dos pastos de capim-tanzânia promovem mudanças na estrutura do dossel aumentando a participação de material morto e de colmos na massa de forragem em pré-pastejo.

3. Maior acúmulo de forragem é registrado em pastos com 95\% de interceptação de luz em associação com resíduo de $25 \mathrm{~cm}$ em capim-tanzânia.

4. O pastejo rotativo do capim-tanzânia deve ser iniciado com $95 \%$ de interceptação de luz do dossel, ou seja, com plantas de $70 \mathrm{~cm}$ de altura, e rebaixados a $25 \mathrm{~cm}$ de altura de resíduo pós-postejo.

\section{Agradecimentos}

À Fundação de Apoio ao Desenvolvimento do Ensino, Ciência e Tecnologia do Estado de Mato Grosso do Sul (Fundect), pelo financiamento parcial deste projeto; ao $\mathrm{CNPq}$, pela concessão de bolsa de estudo ao primeiro autor.

\section{Referências}

BARBOSA, R.A. Características morfofisiológicas e acúmulo de forragem em capim Tanzânia (Panicum maximum Jacq. cv. Tanzânia) submetido a freqüências e intensidades de pastejo. 2004. 122p. Tese (Doutorado) - Universidade Federal de Viçosa, Viçosa. Disponível em: <http://www.forragicultura.com.br/arquivos/ RodrigoAmorimBarbosaTeseUFVDZO.pdf $>$. Acesso em: 30 jan. 2007.

BUENO, A.A. de O. Características estruturais do dossel forrageiro, valor nutritivo e produção de forragem em pastos de capim Mombaça submetidos a regimes de lotação intermitente. 2003. 124p. Dissertação (Mestrado) - Escola Superior de Agricultura Luiz de Queiroz, Piracicaba. Disponível em: <http:// www.teses.usp.br/teses/disponiveis/11/11139/tde-28072003142554/>. Acesso em: 30 jan. 2007.

BUXTON, D.R.; FALES, S.L. Plant environment and quality. In: FAHEY JUNIOR, G.C. (Ed.). Forage quality, evaluation and utilization. Lincoln: University of Nebraska, 1994. p.155-199.

CARNEVALLI, R.A.; SILVA, S.C. da; BUENO, A.A. de O.; UEBELE, M.C.; HODGSON, J.; SILVA, G.N.; MORAIS, J.P.G. Herbage production and grazing losses in Panicum maximum cv. Mombaça under four grazing managements. Tropical Grasslands, v.40, p.165-176, 2006.

EMBRAPA. Centro Nacional de Pesquisa de Solos (Rio de Janeiro, RJ). Sistema brasileiro de classificação de solos. Brasília: Embrapa-SPI; Rio de Janeiro: Embrapa-CNPS, 1999. 412p.

FULKERSON, W.J.; SLACK, K. Leaf number as a criterion for determining defoliation time for Lolium perenne. 1. Effect of watersoluble carbohydrates and senescence. Grass and Forage Science, v.49, p.373-377, 1994.

GRANT, S.A.; BARTHRAM, G.T.; TORVEL, L.; KING, J.; ELSTONJ, D.A. Comparison of herbage production under continuous stocking and intermittent grazing. Grass and Forage Science, v.43, p.29-39, 1988.

HODGSON, J. Grazing management: science into practice. New York: Wiley, 1990. 203p.

HODGSON, J. The significance of sward characteristics in the management of temperate sown pastures. In: INTERNATIONAL GRASSLAND CONGRESS, 15., Kyoto, 1985. Proceedings. Nagoya: Japanese Society of Grassland Science, 1985. p.63-66.

HODGSON, J.; SILVA, S.C. da. Options in tropical pasture management. In: REUNIÃO ANUAL DA SOCIEDADE BRASILEIRA 
DE ZOOTECNIA, 39., 2002, Recife. Anais. Recife: Sociedade Brasileira de Zootecnia, 2002. p.180-202.

LUPINACCI, A.V. Lançamento de cultivares de plantas forrageiras: uma visão crítica. In: SIMPÓSIO SOBRE MANEJO DA PASTAGEM, 20., 2003, Piracicaba. Anais. Piracicaba: Fealq, 2003. p.83-104.

MELLO, A.C.L. Respostas morfofisiológicas do capim Tanzânia (Panicum maximum Jacq. cv. Tanzânia) irrigado à intensidade de desfolha sob lotação rotacionada. 2002. 67p. Tese (Doutorado) - Escola Superior de Agricultura Luiz de Queiroz, Piracicaba. Disponível em: <http://www.teses.usp.br/teses/disponiveis/11/ 11139/tde-25102002-095854/>. Acesso em: 30 jan. 2007.

PEDREIRA, C.G.S.; ROSSETO, F.A. de A.; SILVA, S.C. da; NUSSIO, L.G.; MORENO, L.S. de B.; LIMA, M.L.P.; LEME, P.R. Forage yield and grazing efficiency on rotationally stocked pastures of 'Tanzania-1' guineagrass and 'Guaçu' elephantgrass. Scientia Agricola, v.62, p.433-439, 2005.

SAS INSTITUTE (Cary, Estados Unidos). SAS/STAT user's guide: statistics. Version 6. $4^{\text {th }}$ ed. Cary, 1993. 2v.

SILVA, S.C. da. Fundamentos para o manejo do pastejo de plantas forrageiras dos gêneros Brachiaria e Panicum. In: SIMPÓSIO SOBRE MANEJO ESTRATÉGICO DA PASTAGEM, 2., 2004, Viçosa. Anais. Viçosa: UFV, DZO, 2004. p.347-386.

UEBELE, M.C. Padrões demográficos de perfilhamento e produção de forragem em pastos de capim Mombaça submetidos a regimes de lotação intermitente. 2002. 83p. Dissertação (Mestrado) - Escola Superior de Agricultura Luiz de Queiroz, Piracicaba. Disponível em: <http://www.teses.usp.br/teses/disponiveis/11/11139/ tde-13092002-134643/>. Acesso em: 30 jan. 2007.

Recebido em 21 de junho de 2006 e aprovado em 11 de janeiro de 2007 